\title{
The Content Analysis of Amino Acids in Auricularia auricula from Heilongjiang and Jilin
}

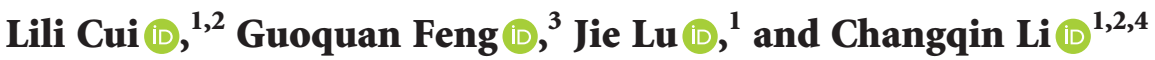 \\ ${ }^{1}$ National RङD Center for Edible Fungus Processing Technology, Henan University, Kaifeng 475004, China \\ ${ }^{2}$ Functional Food Engineering Technology Research Center, Henan Province, Kaifeng 475004, China \\ ${ }^{3}$ International School of Qiushi, Kaifeng 475009, China \\ ${ }^{4} J o i n t$ International Research Laboratory of Food \& Medicine Resource Function, Henan Province, Henan University, \\ Kaifeng 475004, China
}

Correspondence should be addressed to Changqin Li; lcq@vip.henu.edu.cn

Received 28 June 2020; Accepted 16 November 2021; Published 27 November 2021

Academic Editor: Fatma M. El-Demerdash

Copyright (C) 2021 Lili Cui et al. This is an open access article distributed under the Creative Commons Attribution License, which permits unrestricted use, distribution, and reproduction in any medium, provided the original work is properly cited.

\begin{abstract}
The content of amino acids in Auricularia auricula was analyzed by the method of acid hydrolysis and automatic online analysis. The content of total amino acids in A. auricula produced in Heilongjiang was between $68.287 \mathrm{and} 110.949 \mathrm{mg} / \mathrm{g}$, and the average was $90.848 \mathrm{mg} / \mathrm{g}$. The content of essential amino acids in A. auricula from Heilongjiang was between 28.847 and $45.757 \mathrm{mg} / \mathrm{g}$, and the average was $37.987 \mathrm{mg} / \mathrm{g}$. The proportion of essential amino acids (EAA) to total amino acids (TAA) in A. auricula from Heilongjiang was between $41.24 \%$ and $42.26 \%$. However, the content of total amino acids in A. auricula from Jilin was between 71.716 and $124.143 \mathrm{mg} / \mathrm{g}$, and the average was $94.318 \mathrm{mg} / \mathrm{g}$. The content of essential amino acids in A. auricula from Jilin was between 29.775 and $52.063 \mathrm{mg} / \mathrm{g}$, and the average was $38.498 \mathrm{mg} / \mathrm{g}$. The ratio of essential amino acids (EAA) to total amino acids (TAA) in A. auricula from Jilin was between $39.75 \%$ and $41.94 \%$. The content of total amino acids and essential amino acids in A. auricula from Jilin was higher than that from Heilongjiang. However, EAA/TAA in A. auricula from Heilongiiang was higher than that of Jilin. The content of total amino acids in different batches of A. auricula in the same production area was quite different, but the ratio of essential amino acids content to total amino acids content was basically the same.
\end{abstract}

\section{Introduction}

Auricularia auricula is a precious edible and medicinal glial fungus [1] and mostly distributed in temperate regions of the northern hemisphere, mainly in Asia, China, Japan, and other countries, and production of China is higher. In China, Heilongjiang, Jilin, Hubei, Yunnan, Sichuan, Guizhou, Hunan, and Guangxi provinces, A. auricula is cultivated and naturally grown [2]. A. auricula has a thousand years of dual-use history of food and drug in China, first recorded in the "Shennong Herbal Medicine." In the Ming Dynasty, Li Shizhen recorded in the "Compendium of Materia Medica." A. auricula can treat "Duan-gu-zhi-zhi, Yi-qi-bu-ji, and Qing-shen-qiang-zhi" [3]. A. auricula contains a variety of nutrients such as crude polysaccharide, protein, dietary fiber, minerals, and melanin [4], with antioxidant [5], bacteriostasis [6], anticoagulant [7], hypoglycemic [8], and prevention of atherosclerosis [9] and other pharmacological effects. Studies have shown that the protein content in A. auricula was as high as $10.0-16.2 \mathrm{~g} / 100 \mathrm{~g}$ [10]. With the improvement of living standards, people's awareness of healthcare gradually increased, the healthcare function of $A$. auricula gradually give rise to attention, but the quality of $A$. auricula from different production area is uneven. Therefore, the differences of amino acids content in A. auricula produced in two main producing areas (Heilongjiang and Jilin) were analyzed in this study to provide some foundation for the evaluation of nutritional components in A. auricula. 


\section{Materials and Methods}

2.1. Instruments. The content of amino acids in A. auricula was detected on an LC-20A amino acid automatic analyzer (Shimadzu, Japan), equipped with a DUG-20A5R online degassing machine, LC-20AB pump, SIL-20A automatic sampler, CTO-20A column temperature box, and SPD-20A UV detector. The data were analyzed on LabSolutions chromatographic workstation (Shimadzu, Japan). Amino acids specific analysis column (C18, $3 \mu \mathrm{m}, 4.6 \times 150 \mathrm{~mm})$ was purchased from Shimadzu, Japan. 1/10000 electronic balance (ME104/02) was purchased from Swiss Mettler-Toledo Instruments Limited. An Electric blast dryer (DHG-9053A) was purchased from Shanghai Yiheng Scientific Instrument Co., Ltd. Rotary evaporator (EYELA) was purchased from Tokyo Physicochemical Devices Co., Ltd.

2.2. Reagent. Sodium hydrogen phosphate dodecahydrate and sodium tetraborate decahydrate were obtained from the Chinese Medicine Group Chemical Reagent Co., Ltd. (analytical grade). Hydrochloric acid was purchased from Beijing Chemical Factory (superior grade). Methanol and acetonitrile were purchased from Xilong Science Limited (chromatographic grade). Pure water was obtained from Hangzhou Wahaha Group Co., Ltd. 2.5 $\mu \mathrm{M}$ of mixed amino acid standard solution (lot no. 081A1803), internal standard solution (lot no. C3242V01), OPA-derived reagent A liquid (lot no. G4344V02), OPA-derived reagent B liquid (lot no. 129018C02), and FMOC-derived reagents (lot no: F8404V02) were purchased from Shimadzu. All other basic reagents were analytical grade.

2.3. Samples. 10 batches of A. auricula were purchased from market, there into, 5 batches were from Heilongjiang and 5 batches were from Jilin.

2.4. Preparation of Samples. 10 batches of $A$. auricula were crushed over 20 mesh. $0.5 \mathrm{~g}$ of $A$. auricula was accurately weighed, placed in the hydrolytic tube, and $20 \mathrm{~mL}$ of hydrochloric acid $(6 \mathrm{~mol} / \mathrm{L})$ was added. The hydrolysate tube was put into ice and frozen for 3-5 min and then filled with nitrogen and sealed. The hydrolysate tube was then placed in an electrothermal blast dryer, hydrolyzed at $110^{\circ} \mathrm{C}$ for $22 \mathrm{~h}$, and then removed and cooled to room temperature. Then, the hydrolysate was filtered into $50 \mathrm{~mL}$ capacity. The hydrolysate tube was washed with a small amount of water many times, and the water lotion was transferred to the volumetric flask together, and the distilled water was added to the volume to the scale line and shook well.

Accurately take $1.0 \mathrm{~mL}$ of the above constant volume solution in glass bottle with a micropipette, decompress, and concentrate, and $1 \mathrm{~mL}$ of water was added to dissolve the residue after drying, then decompress, concentrate, and steam dry. Then, $1 \mathrm{~mL}$ of sodium citrate buffer solution $(\mathrm{pH}$ 2.2) was added, dissolved, oscillated, and mixed, filter with $0.22 \mu \mathrm{m}$, that is, to get the sample solution. 2 parallel was set for each batch sample.
2.5. Chromatographic Conditions. Chromatographic conditions refer to the AJS-01 amino acid analysis method (Shimadzu). The chromatographic column was special column for amino acid analysis (C18, $3 \mu \mathrm{m}, 4.6 \times 150 \mathrm{~mm}$ ), the column temperature was $50^{\circ} \mathrm{C}$, and the detection wavelengths were $338 \mathrm{~nm}$ and $262 \mathrm{~nm}$. Mobile phase A was buffer ( $\mathrm{pH}$ 8.2) with disodium hydrogen phosphate dodecahydrate and sodium tetraborate decahydrate, and mobile phase B was methanol: acetonitrile: water $(4.5: 4.5$ : 1). The elution gradient and flow rate are given in Table 1.

2.6. Determination of Samples. The mobile phase was arranged according to the method of amino acid analysis of Shimadzu (AJS-01), and the amino acid analysis of A. auricula was carried out by an automatic analyzer of amino acids (LC-20A).

\section{Results}

The content of amino acids for 5 batches of $A$. auricula from Heilongjiang and Jilin was determined, respectively. 16 amino acids were detected, including 7 essential amino acids: threonine, valine, methionine, isoleucine, phenylalanine, lysine, and leucine. The results are given in Tables 2 and 3. In general, the higher amino acids in A. auricula were aspartic acid and glutamic acid. The highest content of essential amino acids was leucine.

In Table 2, the content of total amino acids in A. auricula from Heilongjiang was between 68.287 and $110.949 \mathrm{mg} / \mathrm{g}$, and the average was $90.848 \mathrm{mg} / \mathrm{g}$. The content of essential amino acids in $A$. auricula from Heilongjiang was between 28.847 and $45.757 \mathrm{mg} / \mathrm{g}$, and the average was $37.987 \mathrm{mg} / \mathrm{g}$. The proportion of essential amino acids (EAA) to total amino acids (TAA) in A. auricula from Heilongjiang was between $41.24 \%$ and $42.26 \%$.

In Table 3, the content of total amino acids in A. auricula from Jilin was between 71.716 and $124.143 \mathrm{mg} / \mathrm{g}$, and the average was $94.318 \mathrm{mg} / \mathrm{g}$. The content of essential amino acids in A. auricula from Jilin was between 29.775 and $52.063 \mathrm{mg} / \mathrm{g}$, and the average was $38.498 \mathrm{mg} / \mathrm{g}$. The proportion of essential amino acids (EAA) to total amino acids (TAA) in A. auricula from Jilin was between $39.75 \%$ and $41.94 \% \%$.

\section{Discussion}

Liu et al. [11] determined the content of 17 hydrolysate amino acids in A. auricula from 9 different producing areas in Jilin, Heilongjiang, Liaoning, Hebei, Hubei, Xinjiang, Zhejiang, Jiangxi, and Tibet. The content of 7 essential amino acids in A. auricula produced in Jilin and Heilongjiang was $26.50 \mathrm{mg} / \mathrm{g}$ and $37.07 \mathrm{mg} / \mathrm{g}$, respectively. In this study, the contents of essential amino acids in 5 batches of $A$. auricula produced in Jilin were between 29.775 and $52.063 \mathrm{mg} / \mathrm{g}$ and that in 5 batches of $A$. auricula produced in Heilongjiang were between 28.847 and $45.757 \mathrm{mg} / \mathrm{g}$; the results are basically the same. However, different batches of $A$. auricula from the same origin have a large difference in amino acids content, so if we want to evaluate the quality of $A$. auricula 
TABLE 1: The elution gradient and flow rate.

\begin{tabular}{lcc}
\hline Time $(\mathrm{min})$ & Mobile phase B\% & Flow rate $(\mathrm{mL} / \mathrm{min})$ \\
\hline 0 & 5 & 1.6 \\
6 & 10 & 1.6 \\
8 & 10 & 1.6 \\
10 & 16 & 1.3 \\
23 & 40 & 1.0 \\
30 & 50 & 1.6 \\
31 & 100 & 1.6 \\
34 & 100 & 1.6 \\
35 & 5 & 1.6 \\
38 & 5 & 1.6 \\
\hline
\end{tabular}

TABle 2: Determination of amino acids in A. auricula from Heilongjiang.

\begin{tabular}{|c|c|c|c|c|c|c|c|c|c|c|}
\hline \multirow{2}{*}{$\begin{array}{l}\text { Amino } \\
\text { acids }\end{array}$} & \multicolumn{2}{|c|}{$\mathrm{H} 1$} & \multicolumn{2}{|c|}{$\mathrm{H} 2$} & \multicolumn{2}{|c|}{$\mathrm{H} 3$} & \multicolumn{2}{|c|}{$\mathrm{H} 4$} & \multicolumn{2}{|c|}{ H5 } \\
\hline & $\begin{array}{c}\text { Mean (mg/ } \\
\mathrm{g})\end{array}$ & $\begin{array}{l}\text { Range } \\
(\mathrm{mg} / \mathrm{g})\end{array}$ & $\begin{array}{l}\text { Mean } \\
(\mathrm{mg} / \mathrm{g})\end{array}$ & $\begin{array}{l}\text { Range (mg/ } \\
\text { g) }\end{array}$ & $\begin{array}{l}\text { Mean } \\
(\mathrm{mg} / \mathrm{g})\end{array}$ & $\begin{array}{l}\text { Range } \\
(\mathrm{mg} / \mathrm{g})\end{array}$ & $\begin{array}{l}\text { Mean } \\
(\mathrm{mg} / \mathrm{g})\end{array}$ & $\begin{array}{l}\text { Range } \\
(\mathrm{mg} / \mathrm{g})\end{array}$ & $\begin{array}{l}\text { Mean } \\
(\mathrm{mg} / \mathrm{g})\end{array}$ & $\begin{array}{l}\text { Range } \\
(\mathrm{mg} / \mathrm{g})\end{array}$ \\
\hline Asp & 12.262 & 0.307 & 8.269 & 0.201 & 9.981 & 0.509 & 13.974 & 0.384 & 12.323 & 0.330 \\
\hline Glu & 12.526 & 0.125 & 8.352 & 0.263 & 9.198 & 0.720 & 13.261 & 0.408 & 11.427 & 0.408 \\
\hline Ser & 6.390 & 0.482 & 4.127 & 0.112 & 4.480 & 0.065 & 7.514 & 0.039 & 6.316 & 0.347 \\
\hline His & 3.275 & 0.012 & 2.221 & 0.025 & 2.571 & 0.137 & 2.639 & 0.176 & 2.351 & 0.454 \\
\hline Gly & 5.593 & 0.235 & 3.685 & 0.161 & 4.095 & 0.445 & 5.920 & 0.400 & 5.235 & 0.024 \\
\hline Thr* & 7.531 & 0.335 & 4.984 & 0.109 & 5.877 & 0.101 & 8.407 & 0.106 & 6.669 & 0.412 \\
\hline Arg & 6.067 & 0.137 & 4.035 & 0.079 & 4.366 & 0.296 & 6.795 & 0.298 & 5.460 & 0.135 \\
\hline Ala & 8.290 & 0.084 & 5.520 & 0.180 & 6.332 & 0.426 & 9.361 & 0.327 & 8.092 & 0.053 \\
\hline Tyr & 3.414 & 0.216 & 2.234 & 0.017 & 2.544 & 0.240 & 3.890 & 0.075 & 3.190 & 0.169 \\
\hline Cys-Cys & 1.641 & 0.035 & 1.001 & 0.005 & 1.247 & 0.003 & 1.840 & 0.021 & 1.016 & 0.171 \\
\hline Val $^{*}$ & 6.162 & 0.579 & 3.947 & 0.174 & 4.866 & 0.276 & 6.540 & 0.734 & 6.358 & 0.041 \\
\hline Met* & 4.446 & 1.188 & 3.156 & 0.079 & 3.229 & 1.939 & 4.184 & 0.749 & 3.681 & 0.069 \\
\hline $\mathrm{Ile}^{*}$ & 4.470 & 0.218 & 2.948 & 0.121 & 3.338 & 0.182 & 4.166 & 0.547 & 3.855 & 0.460 \\
\hline $\mathrm{Phe}^{*}$ & 5.398 & 0.077 & 3.596 & 0.049 & 3.973 & 0.174 & 5.353 & 0.315 & 4.200 & 0.296 \\
\hline Lys* & 6.410 & 0.010 & 4.119 & 0.104 & 4.072 & 0.628 & 6.804 & 0.408 & 5.814 & 0.106 \\
\hline Leu* $^{*}$ & 9.095 & 0.002 & 6.099 & 0.153 & 6.744 & 0.442 & 10.304 & 0.676 & 9.147 & 0.174 \\
\hline TAA & 102.966 & 68.287 & 76.910 & 110.949 & 95.131 & & & & & \\
\hline EAA & 43.511 & 28.847 & 32.098 & 45.757 & 39.723 & & & & & \\
\hline $\begin{array}{l}\text { EAA/TAA } \\
\text { (\%) }\end{array}$ & 42.26 & 42.24 & 41.73 & 41.24 & 41.76 & & & & & \\
\hline TAA mean & 90.848 & & & & & & & & & \\
\hline EAA mean & 37.987 & & & & & & & & & \\
\hline
\end{tabular}

*TAA, the content of total amino acids; EAA, the content of essential amino acids; TAA mean, the average of total amino acids content for 5 batches of A. auricula from Heilongjiang; EAA mean, the average of essential amino acids content for 5 batches of A. auricula from Heilongjiang.

from one origin, more than one batch should be selected for experiment.

Wang et al. [12] determined the amino acid content of 8 varieties of $A$. auricula. 16 hydrolyzed amino acids were detected, including 7 essential amino acids. The EAA/TAA of 8 varieties was between $35.61 \%$ and $45.91 \%$, with an average of $39.56 \%$. In this study, the EAA/TAA mean of 10 batches of $A$. auricula was $41.30 \%$, and the data were basically consistent.

Li et al. [13] determined the content of 17 amino acids of A. auricula with different cultivation base materials. The results showed that the total content of 17 amino acids in A. auricula cultivated with mulberry branches was $10.51 \% \pm 0.05 \%$, the total content of 17 amino acids in A. auricula cultivated with wild tussah trees was $8.49 \% \pm 0.08 \%$, and the total content of 17 amino acids in common A. auricula was $9.91 \% \pm 0.05 \%$. It revealed that the content of amino acids in A. auricula with different cultivation bases was different. Yuan et al. [14] analyzed the content of amino acids in A. auricula cultivated with different substrates. The results showed that the content of total amino acids in $A$. auricula cultivated with mulberry, pear, and miscellaneous sawdust was $13.58 \%, 14.08 \%$, and $9.84 \%$, respectively. It was further proved that different cultivation substrates have great influence on the content of amino acids in $A$. auricula. In this study, the cultivation matrix of A. auricula was not clear, but the difference of total amino acids content in different batches of $A$. auricula was obvious from the test results, and the reasons may be different specific areas of origin, different cultivation substrates, and so on.

In addition to the content of amino acids, Liu et al. [11] also analyzed the conventional nutrients of $A$. auricula from different regions. The results showed that the content of ash, 
TABLE 3: Determination of amino acids in A. auricula from Jilin.

\begin{tabular}{|c|c|c|c|c|c|c|c|c|c|c|}
\hline \multirow{2}{*}{$\begin{array}{l}\text { Amino } \\
\text { acids }\end{array}$} & \multicolumn{2}{|c|}{ J1 } & \multicolumn{2}{|c|}{$\mathrm{J} 2$} & \multicolumn{2}{|c|}{ J3 } & \multicolumn{2}{|c|}{$\mathrm{J} 4$} & \multicolumn{2}{|c|}{ J5 } \\
\hline & $\begin{array}{l}\text { Mean } \\
(\mathrm{mg} / \mathrm{g})\end{array}$ & $\begin{array}{l}\text { Range } \\
\text { (mg/g) }\end{array}$ & $\begin{array}{l}\text { Mean } \\
(\mathrm{mg} / \mathrm{g})\end{array}$ & $\begin{array}{l}\text { Range } \\
(\mathrm{mg} / \mathrm{g})\end{array}$ & $\begin{array}{c}\text { Mean (mg/ } \\
\mathrm{g})\end{array}$ & $\begin{array}{l}\text { Range } \\
(\mathrm{mg} / \mathrm{g})\end{array}$ & $\begin{array}{l}\text { Mean } \\
(\mathrm{mg} / \mathrm{g})\end{array}$ & $\begin{array}{l}\text { Range } \\
(\mathrm{mg} / \mathrm{g})\end{array}$ & $\begin{array}{c}\text { Mean } \\
(\mathrm{mg} / \mathrm{g})\end{array}$ & $\begin{array}{l}\text { Range } \\
(\mathrm{mg} / \mathrm{g})\end{array}$ \\
\hline Asp & 9.415 & 0.853 & 11.975 & 1.245 & 11.987 & 0.920 & 12.143 & 0.081 & 15.819 & 1.498 \\
\hline Glu & 8.634 & 0.793 & 12.346 & 1.120 & 11.222 & 0.997 & 11.382 & 0.566 & 14.567 & 1.153 \\
\hline Ser & 5.037 & 0.527 & 6.787 & 0.853 & 6.556 & 0.531 & 5.652 & 0.171 & 7.976 & 0.752 \\
\hline His & 1.716 & 0.314 & 2.609 & 0.385 & 2.385 & 0.264 & 2.042 & 0.236 & 2.839 & 0.245 \\
\hline Gly & 3.733 & 0.332 & 5.169 & 0.359 & 4.521 & 0.266 & 4.436 & 0.022 & 6.802 & 0.458 \\
\hline Thr* & 5.229 & 0.736 & 7.389 & 0.032 & 6.153 & 0.232 & 5.142 & 0.119 & 9.305 & 0.341 \\
\hline Arg & 3.828 & 0.432 & 6.136 & 0.524 & 5.417 & 0.608 & 4.923 & 0.102 & 7.095 & 0.649 \\
\hline Ala & 6.022 & 0.492 & 8.146 & 0.882 & 7.828 & 0.621 & 8.053 & 0.154 & 10.704 & 1.058 \\
\hline Tyr & 2.412 & 0.361 & 3.269 & 0.414 & 3.378 & 0.301 & 2.856 & 0.073 & 4.249 & 0.445 \\
\hline Cys-Cys & 1.146 & 0.070 & 1.496 & 0.318 & 1.321 & 0.070 & 1.047 & 0.095 & 2.032 & 0.195 \\
\hline $\mathrm{Val}^{*}$ & 4.504 & 0.261 & 5.327 & 0.058 & 5.271 & 0.507 & 5.667 & 0.524 & 7.963 & 0.726 \\
\hline Met* & 2.978 & 0.420 & 3.160 & 0.463 & 3.033 & 0.325 & 2.110 & 0.107 & 5.642 & 0.374 \\
\hline $\mathrm{Ile}^{*}$ & 2.910 & 0.176 & 3.859 & 0.066 & 3.287 & 0.310 & 3.275 & 0.083 & 4.862 & 0.401 \\
\hline $\mathrm{Phe}^{*}$ & 3.564 & 0.353 & 5.146 & 0.617 & 4.374 & 0.295 & 4.217 & 0.215 & 5.854 & 0.460 \\
\hline Lys* & 4.168 & 0.346 & 6.495 & 0.720 & 5.668 & 0.484 & 5.243 & 0.059 & 6.985 & 0.489 \\
\hline Leu $^{*}$ & 6.423 & 0.555 & 8.601 & 0.705 & 8.251 & 0.783 & 8.993 & 0.349 & 11.453 & 1.012 \\
\hline TAA & 71.716 & 97.907 & 90.648 & 87.176 & 124.143 & & & & & \\
\hline EAA & 29.775 & 39.976 & 36.035 & 34.644 & 52.063 & & & & & \\
\hline $\begin{array}{l}\text { EAA/TAA } \\
(\%)\end{array}$ & 41.52 & 40.83 & 39.75 & 39.74 & 41.94 & & & & & \\
\hline TAA mean & 94.318 & & & & & & & & & \\
\hline EAA mean & 38.498 & & & & & & & & & \\
\hline
\end{tabular}

${ }^{*}$ TAA, the content of total amino acids; EAA, the content of essential amino acids; TAA mean, the average of total amino acids content for 5 batches of A. auricula from Jilin; EAA mean, the average of essential amino acids content for 5 batches of A. auricula from Jilin.

dietary fiber, and total sugar in A. auricula from Jilin was higher than that from Heilongjiang; however, the content of crude fat, crude protein, and crude polysaccharide in A. auricula from Jilin was lower than that from Heilongjiang. This indicated that the nutrient contents except amino acids of $A$. auricula in different regions were also different.

\section{Conclusion}

The content of total amino acids and essential amino acids in A. auricula from Jilin was higher than that of Heilongjiang. However, EAA/TAA in A. auricula from Heilongjiang was higher than that of Jilin. The content of total amino acids in different batches of A. auricula in the same production area was quite different, but the ratio of essential amino acids content to total amino acids content was basically the same.

\section{Abbreviations}

$\begin{array}{ll}\text { Asp: } & \text { Aspartic acid } \\ \text { Glu: } & \text { Glutamic acid } \\ \text { Ser: } & \text { Serine } \\ \text { His: } & \text { Histidine } \\ \text { Gly: } & \text { Glycine } \\ \text { Thr: } & \text { Threonine } \\ \text { Arg: } & \text { Arginine } \\ \text { Ala: } & \text { Alanine } \\ \text { Tyr: } & \text { Tyrosine } \\ \text { Cys-Cys: } & \text { Cystine-cystine } \\ \text { Val: } & \text { Valine }\end{array}$

$\begin{array}{ll}\text { Met: } & \text { Methionine } \\ \text { Ile: } & \text { Isoleucine } \\ \text { Phe: } & \text { Phenylalanine } \\ \text { Lys: } & \text { Lysine } \\ \text { Leu: } & \text { Leucine } \\ \text { EAA: } & \text { Essential amino acids } \\ \text { TAA: } & \text { Total amino acids. }\end{array}$

\section{Data Availability}

The data used to support the findings of this study are included within the article.

\section{Conflicts of Interest}

The authors declare that there are no conflicts of interest.

\section{Acknowledgments}

This work was funded by the National Key Research and Development Program of China (2018YFD0400200) and Kaifeng Science and Technology Bureau Project (1908007).

\section{References}

[1] R. G. Zhang, X. Q. Diao, and H. N. Guan, "Nutritional health function and product development of Auricularia auricula," Preservation and Processing, vol. 10, no. 1, pp. 54-56, 2010.

[2] Y. J. Liu, Y. Q. Yuan, X. H. Liu, and K. C. Liu, "Research advantances on nutrition and health care of Auricularia auricular," Food and Nutrition in China, vol. 10, pp. 66-69, 2010. 
[3] C. Q. Zhang, "Advances in medicinal studies of Auricularia auricula," Chinese Medicine Science and Technology, vol. 8, no. 5, pp. 339-340, 2001.

[4] Y. Y. Zhang, X. C. Liu, X. Wang, F. Xu, and Y. Y. Ge, "Advances in studies on nutrients and biological activities of Auricularia auricula," South China Agriculture, vol. 12, no. 29, pp. 130-134, 2018.

[5] H. Zhang, Z.-Y. Wang, Z. Zhang, and X. Wang, "Purified Auricularia auricular-judae polysaccharide (AAP I-a) prevents oxidative stress in an ageing mouse model," Carbohydrate Polymers, vol. 84, no. 1, pp. 638-648, 2011.

[6] M. Cai, Y. L. Luo, and P. L. Sun, "Extraction, antimicrobial and monosaccharide composition analysis of polysaccharides from Auricularia auricular," Journal of Zhejiang University of technology, vol. 42, no. 5, pp. 533-538, 2014.

[7] Z. Zhang, D. Liu, B. Xu, and J. Hu, "Liquid- state fermentation with Bacillus subtilis Bs-07 to enhance anticoagulant function of Auricularia auricula polysaccharide," Journal of Southeast University, vol. 31, no. 1, pp. 143-148, 2015.

[8] H. L. Yin, X. Zhao, L. L. Tong, and Z. Y. Wang, "Hypoglycemic function in vitro and in vivo of Auricularia auricula polysaccharides," Food Science, vol. 36, no. 21, pp. 221-226, 2015.

[9] S. F. Guo, Y. X. Cheng, and P. Sun, "Effects of Auricularia auricula polysaccharide on the phenotypes of vascular smooth muscle cells and the expression of bFGF and PDGF in atherogenesis," Journal of Tropical Medicine, vol. 9, no. 8, pp. 868-870, 2009.

[10] X. F. Chen, S. Y. Wei, S. J. Wu, C. Q. Wang, and X. J. Wu, "Analysis and comparison of nutritional components of different strains of Auricularia auricula," Edible Fungi, vol. 38, no. 2, pp. 72-73, 2016.

[11] W. H. Liu, L. Su, and Q. Wang, "Comparative analysis of nutrients in Auricularia auricula from different areas," Northern Horticulture, vol. 05, pp. 121-128, 2020.

[12] M. C. Wang, Preliminary Study on Quality Evalution of Auricularia auricula, Northeast Forestry University, Harbin, China, 2017.

[13] R. X. Li, T. C. Wang, Y. T. Wang, J. F. Xia, W. Wang, and T. Fan, "Comparative analysis of nutrients of three kinds of Auricularia auricula," Journal of Agriculture, vol. 8, no. 3, pp. 48-52, 2018.

[14] W. D. Yuan, X. Tao, W. K. Wang et al., "Effect of different growth substrates on selected nutritional components of Auricularia auricula fruit bodies," Journal of Edible Fungi, vol. 18, no. 2, pp. 45-48, 2011. 